\title{
AS CONCEPÇÕES DE CONTEXTUALIZAÇÃO DO ENSINO EM DOCUMENTOS CURRICULARES OFICIAIS E DE PROFESSORES DE CIÊNCIAS
}

\author{
Conceptions of teaching: contextualization \\ from official curricular documents and from Science teachers
}

\author{
Danilo Seithi Kato ${ }^{1}$ \\ Clarice Sumi Kawasaki
}

Resumo: Apresentam-se diferentes concepções de contextualização do ensino encontradas em documentos curriculares oficiais e em professores de Ensino de Ciências e de Biologia, e discutem-se as implicações pedagógicas dessas concepções para as respectivas áreas, em especial para a organização do trabalho docente. Para identificar essas concepções, analisou-se o conteúdo desses documentos nos diferentes níveis jurisdicionais - federal, estadual (SP) e municipal (SP) -, bem como, da fala de professores de Ciências e de Biologia envolvidos em uma atividade de formação continuada. A análise do potencial pedagógico dessas concepções demonstrou que a diversidade de interpretações sobre este importante princípio curricular pode oferecer, ao professor, possibilidades múltiplas de mediações didáticas em sua difícil tarefa de planejar e organizar o ensino, desde que estas possam ser explicitadas e exploradas nos processos de transposição do ensino dos quais ele participa. Algumas destas possibilidades são aqui exploradas, finalizando o texto.

Palavras-chave: Contextualização. Ensino de Ciências e de Biologia. Propostas curriculares. Professores. Mediações didáticas.

\begin{abstract}
This paper presents different teaching "contextualization" conceptions found in official curricular documents and with teachers from Science Education and Biology areas. We discuss the pedagogical implications of these conceptions to respective areas, especially to the organization of teaching. To indentify these conceptions, this research analyzed the content of these documents in different jurisdictional levels - federal (BR), state (SP) and Hall (SP) - as well as the speech of science and biology teachers involved in an activity of continuous teacher training. The analysis of the pedagogical potential of these conceptions showed that the diversity of interpretations about an important curricular principle can offer numerous possibilities for the teacher, instructional mediations in their difficult tasks of planning and organizing teaching, since these can be explained and explored through the process of transposition education in which the teacher participates. Some of these possibilities are explored in the final text.
\end{abstract}

Keywords: Conceptions. Science education. Curriculum proposals. Teachers. Didactic mediation.

\footnotetext{
${ }^{1}$ Licenciatura em Ciências Biológicas, mestre em Educação. Docente, Departamento de Biologia, Faculdade de Filosofia, Ciências e Letras de Ribeirão Preto, Universidade de São Paulo (FFCLRP-USP). Ribeirão Preto, SP, Brasil.<kato@ffclrp.usp.br>

${ }^{2}$ Licenciatura em Ciências Biológicas, doutora em Educação. Docente, Departamento de Psicologia e Educação, FFCLRP-USP. Ribeirão Preto, SP, Brasil. <sumi@fffclrp.usp.br>

${ }^{1}$ Rua Adalberto Pajuaba, 957, apto. 3D.

Sumarezinho - Ribeirão Preto, SP

14.055-220
} 
Kato, D. S.; Kawasaki, C. S.

\section{Introdução}

A contextualização do ensino e a interdisciplinaridade, segundo as Diretrizes Curriculares Nacionais para o Ensino Médio - DCNEM (BRASIL, 1998), são alguns dos princípios organizadores do currículo do Ensino Médio:

Interdisciplinaridade e contextualização formam o eixo organizador da doutrina curricular expressa na Lei de Diretrizes e Bases da Educação Nacional (1996). Elas abrigam uma visão do conhecimento e das formas de tratá-los para ensinar e para aprender que permite dar significado integrador a duas outras dimensões do currículo de forma a evitar transformá-las em novas dualidades ou reforçar as já existentes: base nacional comum/parte diversificada, e formação geral/preparação básica para o trabalho. (BRASIL, 1998, p.50)

Tais princípios vêm atender o que a Lei de Diretrizes e Bases da Educação Nacional (BRASIL, 1996) estabelece como uma das finalidades do Ensino Médio: a preparação básica para o trabalho e a cidadania do educando, para continuar aprendendo, de modo a ser capaz de se adaptar, com flexibilidade, às novas condições de ocupação ou aperfeiçoamento posteriores.

Em relação ao princípio da contextualização do ensino, apesar de estar presente nos documentos curriculares oficiais mais recentes, o seu significado, para o ensino de um modo geral, não é recente e, tampouco, possui origem nestes documentos. Propostas curriculares, oficiais ou não, anteriores a estes, já o preconizavam sob diferentes termos e formas. A necessidade da contextualização do ensino surgiu em um momento da educação formal no qual os conteúdos escolares eram apresentados de forma fragmentada e isolada, apartados de seus contextos de produção científica, educacional e social. Denominada de ensino tradicional, ainda bastante presente nas práticas escolares, esta visão representa uma tendência pedagógica cuja finalidade tem sido a de levar, ao aluno, o produto final da atividade científica, ou seja, o conhecimento já pronto e organizado, com aura de verdade acabada (FRACALANZA; AMARAL; GOUVEIA, 1986), preocupando-se apenas em disseminar um conhecimento que seja simplesmente reproduzido das situações originais de sua produção, apresentando conteúdos escolares na sua forma mais abstrata. Segundo Lopes (2002), o maior problema em questão é o processo de apropriação do conhecimento pela escola, a retirada dos conceitos de sua historicidade e problemática. Os saberes ensinados aparecem como saberes sem produtores, sem origem, sem lugar, transcendentes ao tempo, ensinando-se apenas o resultado, isolando-os da história de construção do conceito, retirando-os do conjunto de problemas e questões que os originaram. Nesta perspectiva de ensino, os currículos escolares tornam-se inadequados à realidade em que estão inseridos, pois estão centrados em conteúdos muito formais e distantes do mundo vivido pelos alunos, sem qualquer preocupação com os contextos que são mais próximos e significativos para os alunos e sem fazer a ponte entre o que se aprende na escola e o que se faz, vive e observa no dia a dia. É neste âmbito que a contextualização do ensino toma forma e relevância no ensino de ciências, já que se propõe a situar e relacionar os conteúdos escolares a diferentes contextos de sua produção, apropriação e utilização. 
As concepções de contextualização do ensino...

Em virtude de sua origem em diferentes contextos curriculares e educacionais, as interpretações dadas para este importante princípio metodológico do currículo têm sido variadas. Lopes (2002), ao analisar o processo de apropriação de teorias curriculares pelo discurso curricular oficial, obtém, como resultado, o caráter ambíguo do conceito de contextualização nos Parâmetros Curriculares Nacionais do Ensino Médio (BRASIL, 1999). Para esta autora, as ambiguidades são obrigatórias, já que propostas curriculares oficiais podem ser interpretadas como um híbrido de discursos curriculares produzidos por processos de recontextualização, a partir de textos de matizes teóricos distintos. Tais ambiguidades expressam os conflitos, velados ou não, existentes no processo de produção de uma proposta curricular que visa se legitimar na comunidade educacional e, por isso, realiza acordos para tal.

É neste contexto, o da diversidade de significados sobre este princípio organizador do currículo, que se insere a presente reflexão, analisando as implicações pedagógicas destas diretrizes para as práticas do professor enquanto organizador de sua proposta de ensino.

\section{A contextualização do ensino no currículo da escola básica}

Conforme já mencionamos, embora o termo "contextualização do ensino" tenha sido mais explicitamente apresentado nas DCNEM (BRASIL, 1998), o seu significado, para a educação formal, não é nenhuma novidade. Sob diferentes denominações, esta noção já vinha sendo discutida por diferentes autores, conforme apontam os estudos aqui realizados. Nesta revisão, verificou-se que nem sempre estas concepções estavam explicitadas ou claramente definidas por estes autores, o que demandou uma construção das mesmas, a partir das ideias destes autores e de outros referenciados por eles.

Em Rodrigues e Amaral (1996), contextualizar o ensino significa trazer a própria realidade do aluno, não apenas como ponto de partida para o processo de ensino e aprendizagem, mas como o próprio contexto de ensino. Analisam criticamente este princípio nos cursos de formação de professores, buscando as possíveis origens deste discurso e procurando compreender o conceito de "realidade" que está envolvido nesta tradição de ensino.

Moysés (1997) discorre sobre os motivos que levaram o contexto a ser uma condição de aprendizagem. Para tanto, refere-se a uma pesquisa conduzida por Carraher (apud MOYSES, 1997), que investigou as formas pelas quais contramestres de obras e estudantes da $7^{\mathrm{a}}$ série do Ensino Fundamental realizam cálculos de proporções. Em seus resultados, verificouse a superioridade dos mestres de obras em relação aos estudantes na realização destes cálculos, concluindo-se que a familiaridade destes profissionais com esse tipo de relação de proporcionalidade fez com que acertassem as questões. Já, nos estudantes, verificou-se a incapacidade no uso sistemático do algoritmo da proporção aprendida naquele ano na escola, como, também, a ausência de um espírito crítico para perceber a "insensatez" nas respostas dadas. Assim, trazer os contextos de vivência dos alunos para os contextos de aprendizagem torna-se um importante fator de aprendizagem, pois dá sentido aos conhecimentos aprendidos. Ao professor, cabe o papel de apresentar, aos estudantes, uma forma de ler, interpretar e intervir neste conjunto de vivências e no mundo em que vivem. 
Kato, D. S.; Kawasaki, C. S.

Lima et al. (2000), a partir de uma crítica ao ensino de química não contextualizado - cuja prática tem-se limitado a cálculos matemáticos, memorização de fórmulas e nomenclaturas de compostos e sem a valorização dos aspectos conceituais e das atividades que envolvem o aluno de uma forma ativa frente ao conhecimento - propõem um ensino alternativo no qual a cinética química é desenvolvida a partir de uma abordagem contextualizada. Para estes autores, a contextualização do ensino ocorre quando são considerados os conhecimentos prévios e o cotidiano dos alunos. Observaram que os conceitos citados após a intervenção - que tinha como ponto de partida a experiência cotidiana dos alunos com a questão da conservação de alimentos - haviam alcançado o objetivo educacional proposto.

Lopes, Gomes e Lima (2001) analisam, no texto oficial dos Parâmetros Curriculares Nacionais do Ensino Médio (BRASIL, 1998), as relações entre os conteúdos das diversas disciplinas da área de Ciências da Natureza, Matemática e suas Tecnologias e os contextos de vida dos alunos, procurando saber quais são aqueles considerados importantes em cada uma destas disciplinas. Os autores buscam focalizar a concepção de contextualização presente em cada uma das disciplinas das ciências naturais, buscando entender como estas se articulam às orientações das DCNEM (BRASIL, 1998), e qual o seu potencial para superar a classificação disciplinar acentuada do Ensino Médio. Em seus resultados, os autores identificam um misto de concepções, mas que, em síntese, evidenciam a ideia de aproximação dos conteúdos científicos ao cotidiano do aluno, estreitando essa relação e produzindo conhecimento no ambiente escolar.

Lopes (2002), uma das autoras do artigo anterior, ao procurar entender a influência do discurso curricular oficial sobre a produção do conhecimento escolar, buscando interpretar o processo de apropriação de teorias curriculares nesta produção, identifica a presença de um discurso curricular híbrido nos PCNEM (BRASIL, 1999) e o caráter ambíguo do conceito de contextualização. Neste discurso híbrido, analisa as ambiguidades expressas pelo conceito de contextualização no conhecimento oficial, destacando três interpretações para 'contexto' nas orientações curriculares para o Ensino Médio: a) trabalho; b) cidadania, e c) vida pessoal, cotidiana e convivência. De forma geral, é conferida centralidade ao contexto do trabalho, ficando os dois outros contextos subsumidos a ele. Esta centralidade do trabalho está expressa na escolha da tecnologia, como tema por excelência capaz de contextualizar os conhecimentos e as disciplinas no mundo produtivo e como princípio integrador de cada uma das áreas. Nesta perspectiva, permanece a ideia unilateral de que a educação tem por finalidade a inserção social no mundo produtivo, sem questionamento do projeto de construção desse mesmo mundo, limitando a dimensão cultural da educação. Ao analisar as ambiguidades no conceito de contextualização, a autora busca referências em outros autores, tais como: Dewey, Stein, Piaget e Vigotsky. Uma breve explanação das ideias destes autores é apresentada a seguir, buscando-se esclarecer algumas destas ambiguidades apontadas por esta autora.

Para Dewey (1959), o conhecimento e seu desenvolvimento são concebidos como um processo social, integrando os conceitos de sociedade e indivíduo. A partir desta premissa, entende que a educação deve integrar-se às experiências de vida do estudante como cidadão, pessoa e ser humano - a denominada "educação para a vida", a qual permitirá, ao aluno, desenvolver a sua capacidade de raciocínio e espírito crítico, principais metas da educação.

A “aprendizagem situada" de Stein (1998) é outra referência para o conceito de contextualização encontrada nas DCNEM (BRASIL, 1998). Para este autor, esta aprendizagem é 
As concepções de contextualização do ensino...

uma estratégia instrucional que busca relacionar a matéria escolar às necessidades dos aprendizes. Para o autor, aprender é essencialmente criar significados para as atividades reais do dia a dia e, para isso, o ensino deve oferecer ambientes e atividades que propiciem a vivência destas situações reais, concretas e práticas. Para Lopes (2002), a aprendizagem situada de Stein procura colocar o pensamento e a ação em um lugar específico de significado, envolver os aprendizes, o ambiente e as atividades para produzir significado. Todo conhecimento é construído de forma situada, em determinado contexto, de maneira a ser transferido para situações similares.

As teorias interacionistas de Jean Piaget (1896-1980) e de Lev Semyonovitch Vigotsky (1896-1934), que enfatizam a interação entre o organismo e o meio na aquisição do conhecimento, são importantes bases para valorizar a busca de contextos significativos nos processos de ensino e aprendizagem. Na perspectiva de Vigotsky (1987), o sujeito não é apenas ativo, regulado por forças internas, mas interativo, porque constitui conhecimentos e se constitui a partir de relações intra e interpessoais. Para Vigotsky (1987), é na troca com outros sujeitos, experiência, hábitos, atitudes, valores e a própria linguagem daqueles que interagem com o sujeito, que se conhece, que se vão internalizando conhecimentos, papéis e funções sociais, o que permite a constituição de conhecimentos e da própria consciência. Em suma, apesar de estes dois autores não terem abordado diretamente a questão da contextualização do ensino, desenvolveram ideias que ajudam a compreender a construção desta noção nos documentos curriculares oficiais. A consideração do contexto de vida de quem aprende, seja em seu âmbito pessoal, profissional ou social, demonstra a necessidade de se incluírem, nas práticas pedagógicas, atividades de ensino articuladas com as experiências de vida destes aprendizes.

Para Ramos (2002), a contextualização do ensino é um recurso para ampliar as possibilidades de interação não apenas entre as disciplinas nucleadas em uma área de conhecimento (entre as próprias áreas de nucleação), como, também, entre esses conhecimentos e a realidade do aluno. Busca-se, nesta abordagem, a inserção do conhecimento disciplinar em uma realidade plena de vivências, incluindo aspectos e questões presentes na sociedade e no cotidiano do aluno, tais como: a melhoria da qualidade de vida e as relações entre Ciência, Tecnologia e Sociedade (CTS). Em síntese, contextualizar o ensino é aproximar o conteúdo formal (científico) do conhecimento trazido pelo aluno (não formal), para que o conteúdo escolar torne-se interessante e significativo para ele. Nesse sentido, a contextualização evocaria áreas, âmbitos ou dimensões presentes na vida pessoal, social e cultural, mobilizando competências cognitivas já adquiridas.

A partir destes estudos, foi possível identificar 11 concepções de contextualização do ensino, que se originaram dos contextos significativos apontados por estes autores para o ensino de ciências, quais sejam: realidade, vida, vivência, mundo, cotidiano, trabalho, cidadania, contexto social, contexto histórico e cultural, conhecimentos prévios do aluno e disciplinas escolares. Estas concepções foram organizadas e reunidas em 3 agrupamentos, constituindo as primeiras categorias de análise destas concepções: a) a que reúne as concepções relacionadas ao cotidiano do aluno; b) a que reúne as concepções relacionadas à(s) disciplina(s) escolar(es), e c) a que reúne as concepções relacionadas a contextos histórico, social e cultural. 
Kato, D. S.; Kawasaki, C. S.

\section{A pesquisa sobre concepções de contextualização do ensino em documentos curriculares e de professores de Ciências e de Biologia}

Foi durante as oficinas de um curso de formação continuada de professores de ciências e de biologia, que a questão da contextualização do ensino surgiu, pela primeira vez, como um importante tema de investigação para o mestrado. Nestas oficinas, apesar da importância atribuída pelos professores ao ensino contextualizado, não havia, entre eles, uma mesma compreensão sobre este tema para o ensino de ciências. Em virtude disso, havia muita dificuldade na implementação deste princípio organizador do currículo, já que cada uma das concepções encontradas nos professores conduzia a uma forma diferenciada de aplicação. Este fato disparou a necessidade de um aprofundamento maior sobre este tema, resultando em uma dissertação, cuja questão central foi: "O que é contextualização do ensino e qual é o seu significado pedagógico para o ensino de ciências e de biologia?”. Resultados desta pesquisa, que analisou textos dos documentos curriculares oficiais e a fala de professores das áreas de ciências e biologia, demonstraram que não havia um conceito único e coeso de contextualização, e sim diferentes concepções que, ao serem analisadas, traziam diferentes implicações para o ensino de ciências. Antes de apresentar estes resultados, vamos conhecer os materiais, sujeitos e os procedimentos metodológicos desta pesquisa.

\section{Metodologia da pesquisa: materiais analisados, sujeitos e procedimentos de coleta e análise}

Os textos dos documentos curriculares oficiais analisados abrangem diferentes níveis escolares do Ensino Básico e diferentes níveis jurisdicionais - federal, estadual (SP) e municipal (SP) - sendo, para o Ensino Médio, as Diretrizes Curriculares Nacionais para o Ensino Médio/DCNEM (BRASIL, 1998), os Parâmetros Curriculares Nacionais para o Ensino Médio/PCNEM (BRASIL, 1999) e a Proposta Curricular para o Ensino de Biologia para o $2^{\circ}$ grau/PCEB" (SÃO PAULO, 1988); e, para o Ensino Fundamental, os Parâmetros Curriculares Nacionais para o Ensino Fundamental/PCNEF" (BRASIL, 1998b), a Proposta Curricular para o Ensino de Ciências e Programas de Saúde para o $1^{\circ}$ grau/PCEC" (SÃO PAULO, 1991) e o Movimento de Reorientação Curricular de Ciências/MRCC (SÃO PAULO, 1992). Esses documentos foram selecionados em virtude de sua abrangência e relevância para o sistema estadual (SP) de ensino, contexto em que se situam os professores sujeitos desta pesquisa.

Os sujeitos desta pesquisa, os professores de ciências e de biologia, são participantes de um curso de formação continuada promovido por uma universidade pública, que realizou encontros semanais (quatro horas) durante todo o ano de 2004. Reuniam-se, nesses encontros, cerca de sete a dez professores, que tinham como proposta discutir a temática da Biodiversidade no Ensino de Ciências e de Biologia. A questão da contextualização do ensino surgiu em três dos 16 encontros realizados, sendo que, em um deles, esta questão foi o foco principal das discussões. A análise da fala destes professores incidiu sobre o registro em áudio e vídeo destes três encontros.

Tanto os textos dos documentos curriculares como a fala destes professores foram analisados em sua íntegra, dentro de uma abordagem qualitativa da pesquisa educacional (BOGDAN; BIKLEN, 1994) e por meio da técnica de análise do conteúdo (BARDIN, 2009), cum- 
As concepções de contextualização do ensino...

prindo os seguintes procedimentos: descrição (enumeração de características do texto, frequência e categorização), inferência (operações lógicas pela qual se admite uma proposição pela sua ligação com outras proposições já aceitas), e interpretação (compreender o sentido da comunicação). A pré-análise, por meio de uma leitura flutuante, escolha dos documentos, formulação de hipóteses e objetivos e criação de indicadores, compôs a fase inicial do trabalho.

Segundo Bardin (2009), a regra da exaustividade na análise documental garante que não se deixe nenhum elemento de fora da possibilidade de análise, por isso os documentos oficiais foram exaustivamente lidos, buscando-se o aparecimento do termo contextualização. O termo contextualização foi a unidade de registro utilizada para uma análise prévia, a partir da qual se criaram os indicadores que permitiram a organização das categorias construídas. Pela regra da pertinência, delimitou-se, como critérios, o nível de abrangência de cada documento - municipal, estadual e federal.

A revisão de estudos sobre a contextualização do ensino e suas implicações educacionais, conforme apresentada no tópico anterior, trouxe os referenciais iniciais para identificar e analisar as concepções encontradas nos documentos e nos professores. A partir disso, foram criadas três categorias de análise, conforme já mencionado. Todavia, estas categorias não foram suficientes para abranger as demais concepções encontradas nos documentos curriculares e nos professores, levando-nos a criar novas categorias que emergiram dos próprios textos dos documentos curriculares e das transcrições dos três encontros deste curso de formação de professores. Ao final deste estudo, resultaram cinco categorias de análise, conforme veremos no tópico seguinte.

\section{Resultados e conclusões da pesquisa}

Foram identificadas dez concepções de contextualização do ensino nos documentos curriculares oficiais, que foram organizadas em cinco categorias de análise, conforme mostra o Quadro 1.

Nas DCNEM (BRASIL, 1988), duas categorias estão presentes. A perspectiva de associar o conteúdo da disciplina às experiências de vida do aluno ou aos conhecimentos adquiridos anteriormente pelo aluno, buscando retirar o aluno da condição de espectador passivo e tornar a aprendizagem mais significativa para ele, traz a categoria de análise "cotidiano do aluno". Sem perder o essencial da aprendizagem escolar, que é o seu caráter sistemático, consciente e deliberado, o processo de ensino busca provocar aprendizagens significativas que mobilizem o aluno, estabelecendo, entre ele e o objeto do conhecimento, uma relação de reciprocidade. A contextualização evoca, por isto, áreas, âmbitos ou dimensões presentes na vida pessoal, social e cultural, e mobiliza competências cognitivas já adquiridas. O trabalho e a cidadania estão previstos como os principais contextos desta categoria. A noção de que contextualizar é integrar o conteúdo específico de sua área a conteúdos das demais disciplinas do currículo escolar, propondo uma abordagem interdisciplinar do conhecimento, remete-nos à segunda categoria, a da "disciplina(s) escolar(es)".

Os PCNEM (BRASIL, 1999) são o documento que mais reúne concepções diferenciadas de contextualização do ensino, relacionadas às cinco categorias de análise. Ao final das discussões de cada uma das áreas específicas do Bloco "Ciências da Natureza, Matemática e 
Kato, D. S.; Kawasaki, C. S.

suas Tecnologias", propõe-se o desenvolvimento de um tópico denominado "Contextualização siciocultural", no qual se definem objetivos e conteúdos de ensino que incluem aspectos da sociedade e do modo de vida contemporâneo, envolvendo, assim, todos os contextos encontrados nestas cinco categorias.

Nos PCNEF (BRASIL, 1998), não há referência direta ao termo contextualização, mas há diversos elementos que remetem à ideia de contextualização. A proposta de organização do currículo de ciências por meio de eixos temáticos é um desses elementos, já que permite romper com uma visão fragmentada das áreas das Ciências, propondo situar e abordar o conteúdo escolar de forma integrada dentro da própria área de ciências (intradisciplinar) e com outras áreas curriculares (interdisciplinar). Além disso, ao propor os temas transversais, busca trazer a realidade sociocultural do aluno para o ensino e, também, abordar este conteúdo de forma mais integrada. Não foram encontradas concepções relacionadas à categoria de análise "ciência".

Na PCEB (SÃO PAULO, 1988), a noção de contextualização do ensino apresenta-se diretamente relacionada aos conteúdos biológicos, já que afirma a relevância do contexto social no ensino e processo de produção do conhecimento, para que o aluno conheça não apenas o produto da ciência (biológica), mas, também, os processos de produção do conhecimento científico (biológico). Assim, neste documento, além das concepções relacionadas à categoria "ciência", foram encontradas aquelas relacionadas à categoria "cotidiano do aluno".

No MRCC (SÃO PAULO, 1992), a contextualização não é um princípio explícito, tal como ocorre com a noção de interdisciplinaridade, que, no presente documento, é adotada como o percurso metodológico para se chegar a um currículo mais dinâmico e crítico. Contudo, evidencia a necessidade de se compreenderem as relações entre o individual e o coletivo na formação de um cidadão crítico e ativo socialmente, afirmando que essa compreensão só poderá ocorrer por meio da utilização do senso comum, da realidade vivenciada como ponto de partida para discussões teóricas, trazendo a categoria "cotidiano do aluno".

A partir desses resultados, foi possível concluir que as concepções de contextualização do ensino mais presentes nos documentos curriculares encontram-se na categoria "cotidiano do aluno", já que relacionam o conteúdo da disciplina à realidade, à cidadania, ao mundo do trabalho e às experiências pessoais e sociais do aluno. A categoria "disciplina(s) escolar(es)", que busca relações entre os conteúdos das ciências naturais e destes com outras disciplinas escolares, numa perspectiva multi, trans ou interdisciplinar, é a segunda perspectiva mais presente (com exceção do documento MRCC, 1992). O documento das DCNEM (1988) é o que reúne concepções de todas as cinco categorias de análise. Já, a PCEB é o único documento a apresentar uma concepção de contextualização no ensino que busca relações entre o conhecimento biológico das ciências e teorias mais gerais da biologia e da ciência. $\mathrm{O}$ documento do MRCC (ano) foi o que apresentou menos variedade de concepções, inserindo-se em apenas duas categorias de análise.

Já, entre os professores de ciências e de biologia, sujeitos desta pesquisa, foram identificadas três concepções, que se relacionam a três categorias de análise já existentes: "cotidiano do aluno", "disciplina(s) escolar(es) e "contextos histórico, social e cultural". 
As concepções de contextualização do ensino...

\section{Na categoria "cotidiano do aluno"}

O pesquisador 1, segundo o trecho abaixo e intervenções pontuais ao longo da oficina, aponta a importância de trazer o cotidiano do aluno para o ensino de ciências. Para ele, cotidiano significa o ambiente imediato e vivencial do aluno; já que a tundra é considerada, por ele, um ecossistema distante deste ambiente imediato do aluno, este não faria parte de seu cotidiano.

'[...] Não adianta você pegar um panorama ali qualquer pro cara sem saber se ele realmente conbece aquilo minimamente, senão, não há contexto. Então, vamos pensar assim: um cara que foi criado numa comunidade tradicional, uma comunidade ribeirinha tá. O cara nunca na vida dele assistiu televisão. Aí você vai dar aula pra ele, eu só tô fažendo uma situação bipotética pra gente ver (_ então eu vou ensinar pra ele o que é um ecossistema. Então eu digo assim pra ele: Nossa aula vai comecar hoje com Tundra." (pesquisador 1)

Em Fracalanza, Amaral e Gouveia (1986), a preocupação com a abordagem do cotidiano, nos processos de Contextualização, não é uma forma de banalizar ou restringir os conhecimentos dos alunos ou limitá-lo à realidade imediata, fazendo dela a única realidade possível de ser conhecida. Esse pesquisador evidencia sua preocupação com a posição do aprendiz frente ao que está sendo criado, uma vez que aplicar, a princípio, um conceito totalmente abstrato ao aluno é imediatamente criar uma primeira barreira ao processo ensinoaprendizagem que será difícil de vencer a posteriori, prejudicando todo o processo de compreensão do objeto. Se a Contextualização é para que o aluno possa compreender melhor seu conteúdo escolar, ele precisa compreender o contexto e agir sobre ele.

Nos PCNEM (1999) aparece o termo "prático" para um ensino Contextualizado, ou seja, concreto e palpável ao aluno, o que reforça a opinião do pesquisador 1. Dessa forma, defende um ensino de sentido concreto para o aluno, dentro de sua realidade, o que o documento denomina contextualização no ensino. A partir dessa realidade cotidiana, atingir níveis complexos de abstrações do objeto pertencente a sua realidade de vivências.

\section{Na categoria "disciplinas escolares"}

Para o professor 7, contextualizar é integrar o conteúdo a ser ensinado com outros conteúdos, de forma a criar um contexto. Para ele, a relação entre a Contextualização e a Interdisciplinaridade ocorre devido à articulação entre diferentes áreas do conhecimento na criação de contextos, que, de forma geral, apresentam relações entre conteúdos específicos de áreas distintas na construção de uma situação manipulável. O professor 7, do grupo de ensino (GE), mostra essa concepção de contextualização como recurso para interligar conteúdos.

'[...] contextualização de outra forma também, por exemplo, agora você pode Contextualizar com outras... outras... áreas também. Poderia de repente esco- 
Kato, D. S.; Kawasaki, C. S.

Iher uma música também, ou trabalhar com o ciclo biogeoquimico da água, ou também com a parte biológica. Você fazer uma conexão de conceitos também." (professor 7)

A fala do professor 7 não estabelece como as ligações entre os conceitos ocorrem, tampouco se essa articulação é dentro de uma mesma área de nucleação ou entre áreas distintas. A criação de um contexto ocorre por meio da conexão entre conceitos específicos.

O pesquisador abaixo parte de uma crítica aos PCN em geral, afirmando que, nestes, não há uma indicação de mecanismos para realização da contextualização. Este pesquisador também apresenta uma concepção de contextualização relacionada à ideia de integração entre disciplinas e áreas, pois, indica a dificuldade em relacionar conceitos diferentes no exato momento em que se discutia a concepção de contextualização na perspectiva da integração das disciplinas. Há a crítica aos PCN, que não propõem a forma como se podem estabelecer as relações entre os conteúdos. O pesquisador faz referência a outras propostas que o subsidiam melhor. Assim, percebe-se que a escolha do documento representa uma concepção de contextualização e a dificuldade de colocar em prática essas representação seria, para esse pesquisador, o ato de contextualizar o ensino.

\section{'[...] É porque diferente do que quando você pega uma proposta curricular pareci- da com aquele caderninho verde, e o que ta proposto para Ciências que é um caderninho vermelho, né? Onde lá você tem realmente conceitos que se interligam, né... então você pega, por exemplo, energia, matéria, transformação e você fala então esse é o conceito. Agora no PCN.” (pesquisador 1)}

A fala acima reforça a ideia anteriormente discutida de que os documentos realmente não auxiliam o professor no sentido de apresentarem possibilidades metodológicas para a realização da contextualização do ensino.

\section{Na categoria "histórico e sociocultural"}

O pesquisador 2 e demais participantes da oficina buscam relacionar parte/todo em um movimento de articular o conteúdo a ser ensinado a um contexto mais amplo. O foco é a própria historicização do objeto de aprendizagem. Este entrevistado apresenta, ainda, como exemplo, o caso do conceito adaptação, que é a parte a ser inserida em um universo mais abrangente, ou seja, ao campo do conhecimento científico a que está ligado. Alguns professores trazem, ainda, a ideia de contextualizar por meio do conhecimento das relações entre o objeto de aprendizagem e o meio em que está inserido, ou seja, diferentemente da perspectiva do cotidiano do aluno, o foco, agora, é o cotidiano do objeto a ser conhecido.

'[...] É procurar uma parte dentro de um todo... eu acho que assim, a idéia de Contextualizar é você pegar a parte, então, por exemplo, você vai pegar o conceito de adaptação, e você remete ao todo que ele pertence, né...”. (pesquisador 2) 
As concepções de contextualização do ensino...

Como discutido no início do artigo em termos gerais, a contextualização no ensino de ciências abarca competências de inserção da ciência e de suas tecnologias em um processo histórico, social e cultural; e, também, o reconhecimento e discussão de aspectos práticos e éticos da ciência no mundo contemporâneo.

O Quadro 1 sintetiza as cinco categorias de análise que resultaram das concepções de contextualização do ensino identificadas nesta pesquisa.

Quadro 1. Categorias de análise das concepções de contextualização do ensino, contextos de significação e de ocorrência destas concepções.

\begin{tabular}{|c|c|c|c|}
\hline Categorias de análise & Concepções & $\begin{array}{l}\text { Contextos de } \\
\text { significação }\end{array}$ & $\begin{array}{l}\text { Documentos ou } \\
\text { professores }\end{array}$ \\
\hline \multirow[t]{2}{*}{ 1) Cotidiano do aluno } & $\begin{array}{l}\text { Buscar relações com as experiências } \\
\text { pessoais e sociais do aluno, a } \\
\text { realidade do aluno e a cidadania. }\end{array}$ & Cotidiano do aluno & $\begin{array}{l}\text { DCNEM/PCNEM/ } \\
\text { PCEB/PCNEF/ } \\
\text { PCEC/MRCC } \\
\text { Professores }\end{array}$ \\
\hline & $\begin{array}{l}\text { Buscar relações com o mundo do } \\
\text { trabalho. }\end{array}$ & Mundo do trabalho & DCNEM \\
\hline $\begin{array}{l}\text { 2) Disciplina(s) } \\
\text { escolar(es) }\end{array}$ & $\begin{array}{l}\text { Buscar relações com outras } \\
\text { disciplinas (multi, trans ou } \\
\text { interdisciplinaridade). }\end{array}$ & $\begin{array}{l}\text { Outras disciplinas } \\
\text { escolares }\end{array}$ & $\begin{array}{l}\text { DCNEM/PCNEM/ } \\
\text { PCNEF/PCEC } \\
\text { Professores }\end{array}$ \\
\hline \multirow[t]{2}{*}{ 3) Ciência } & $\begin{array}{l}\text { Buscar relações com a ciência, } \\
\text { enquanto produto e processo. }\end{array}$ & Universo da ciência & PCNEM/PCEC \\
\hline & $\begin{array}{l}\text { Buscar relações com as ciências } \\
\text { naturais, em especial, as ciências } \\
\text { biológicas (as teorias evolutivas). }\end{array}$ & $\begin{array}{l}\text { Teorias gerais da } \\
\text { Biologia e da ciência }\end{array}$ & PCEB \\
\hline \multirow[t]{2}{*}{ 4) Ensino } & $\begin{array}{l}\text { Buscar relações entre conhecimento } \\
\text { científico e conhecimento escolar. }\end{array}$ & $\begin{array}{l}\text { Conhecimento } \\
\text { científico }\end{array}$ & PCNEM \\
\hline & $\begin{array}{l}\text { Buscar problematizar e situar o } \\
\text { conhecimento escolar em relação a } \\
\text { outras formas de conhecimento. }\end{array}$ & $\begin{array}{l}\text { Diversas formas de } \\
\text { conhecimento em } \\
\text { diferentes contextos }\end{array}$ & $\begin{array}{l}\text { PCNEF/PCECI } \\
\text { MRCC }\end{array}$ \\
\hline \multirow[t]{3}{*}{$\begin{array}{l}\text { 5) Contexto histórico, } \\
\text { social e cultural }\end{array}$} & $\begin{array}{l}\text { Buscar relações com elementos da } \\
\text { cultura. }\end{array}$ & $\begin{array}{l}\text { Cultura brasileira e } \\
\text { mundial }\end{array}$ & $\begin{array}{l}\text { PCNEM/PCNEF/ } \\
\text { PCEC } \\
\text { Professores }\end{array}$ \\
\hline & $\begin{array}{l}\text { Buscar relações com a história da } \\
\text { ciência. }\end{array}$ & $\begin{array}{l}\text { Contexto histórico e } \\
\text { social }\end{array}$ & PCNEM/PCEC \\
\hline & Buscar relações CTS & $\begin{array}{l}\text { Ciência, tecnologia e } \\
\text { sociedade }\end{array}$ & $\begin{array}{l}\text { PCNEM/PCNEF/ } \\
\text { PCEC } \\
\text { Professores }\end{array}$ \\
\hline
\end{tabular}

DCNEM (1998) - Diretrizes Curriculares Nacionais para o Ensino Médio.

PCNEM (1999) - Parâmetros Curriculares Nacionais para o Ensino Médio.

PCEB (1988) - Proposta Curricular para o Ensino de Biologia.

PCNEF (1998) - Parâmetros Curriculares Nacionais para o Ensino Fundamental.

PCEC (1991) - Proposta Curricular para o Ensino de Ciências e Programas de Saúde.

MRCC (1992) - Movimento de Reorientação Curricular - Ciências. 
Kato, D. S.; Kawasaki, C. S.

Observou-se que, apesar de encontrarmos uma multiplicidade de concepções de contextualização do ensino, estas não são contraditórias entre si (ou ambíguas), já que todas elas compartilham da noção de que contextualizar é articular ou situar o conhecimento específico da disciplina (parte) a contextos mais amplos de significação (todo), estes, sim, bastante variados: o cotidiano do aluno, a(s) disciplina(s) escolar(es), a ciência (referência), o ensino e os contextos histórico, social e cultural.

\section{Implicações pedagógicas das concepções de contextualização do ensino para o ensino de Ciências e de Biologia}

Enfrentar uma tradição de ensinar biologia como conhecimento descontextualizado, buscando desenvolver mediações didáticas que permitam transitar do mundo da experiência imediata e espontânea para o plano das abstrações e deste para a reorganização da experiência imediata, deverá ser o principal desafio das práticas escolares, cabendo, ao professor, protagonizar esse processo. Certamente, tal tarefa não será simples e nem fácil.

Entendemos que a diversidade de concepções de contextualização do ensino, identificada nesta pesquisa, pode oferecer, ao professor, possibilidades múltiplas de mediações didáticas em sua difícil tarefa de planejar e organizar o ensino, desde que estas possam ser explicitadas e exploradas, por ele, nos processos de transposição do ensino. Assim, discutiremos as implicações pedagógicas de cada uma delas, apontando estas possibilidades que serão abordadas a partir das cinco categorias que reúnem todas as concepções encontradas.

Em relação à primeira categoria "cotidiano do aluno", a ideia de valorizar o cotidiano no ensino de ciências não representa nenhuma novidade, pois, já no final da década de 1970, havia, no Brasil, as primeiras manifestações sistemáticas a favor deste princípio. Segundo Fracalanza, Amaral e Gouveia (1986), esta ideia tem crescido sistematicamente nos últimos anos, sendo concebida sob duas formas: a primeira, que se preocupa com a aplicação do aprendizado na solução de problemas práticos na vida do estudante e, a segunda, que, sem excluir obrigatoriamente a primeira, propõe o uso do cotidiano como motivação para o aluno, já que, ao partir de seu mundo concreto, o aluno se interessaria mais pelo objeto de estudo e aprenderia mais. Entretanto, para este autor, tanto um caminho quanto o outro cometem equívocos que devem ser enfrentados. O primeiro equívoco é o de que os conteúdos escolares não devem ter compromisso prioritário com a utilidade imediata, mas com a formação intelectual do aluno, ficando as aplicações práticas imediatas como vantagens adicionais. O segundo é considerar o cotidiano do aluno apenas como recurso motivacional, sem que haja uma articulação deste cotidiano com as demais fases da aprendizagem. É bastante frequente partir do cotidiano do aluno no início do processo de aprendizagem e passar para o conteúdo formal, ficando um fosso entre os dois tipos de conhecimento. O terceiro refere-se à noção, sobretudo presente nos livros didáticos, de um cotidiano padronizado e estereotipado, constituindo-se a própria negação do conceito de cotidiano, já que, para muitos deles, este é irreal e abstrato.

As relações estabelecidas com o cotidiano do aluno devem permitir dar significado ao conteúdo curricular, fazendo a ponte entre o que se aprende na escola e o que se faz, vive e observa no dia a dia, mas estas não devem ser confundidas com abordagens espontaneístas e imediatistas deste cotidiano. Sendo assim, os processos de ensino e aprendizagem deverão 
As concepções de contextualização do ensino...

buscar vínculos efetivos com o cotidiano, porém, deverão superá-lo, buscando uma articulação entre este cotidiano e os níveis mais conceituais e abstratos da aprendizagem, num movimento permanente de ação e reflexão.

Para realizar as mediações didáticas entre o cotidiano do aluno e o ensino, é preciso enfrentar as concepções prévias que estes alunos possuem sobre os conteúdos a serem tratados na escola, que encontram-se, via de regra, no plano do senso comum e constituídas por representações equivocadas ou limitadas para a compreensão e a explicação da realidade. Se não enfrentada essa contradição, corre-se o risco de se considerar que a simples sistematização de conhecimento cotidiano seja suficiente para que o aluno estabeleça relações entre ideias, fatos e fenômenos para enfrentar situações concretas que demandem problematizações, elaborações conceituais e soluções (RAMOS, 2002).

Ao contextualizar os conteúdos escolares na perspectiva do cotidiano, surge, naturalmente, a necessidade de contextualizá-los no conjunto das disciplinas escolares, pois somente na perspectiva das disciplinas escolares se completará o processo iniciado na perspectiva anterior, que é o de relacionar aquilo que é aprendido com o aquilo que é vivenciado no cotidiano. Assim, surge a segunda categoria, "disciplina(s) escolare(s)", que procura relacionar ou situar o conhecimento específico no contexto das disciplinas escolares, tanto entre as disciplinas nucleadas na própria área das Ciências Naturais (intradisciplinar) como entre as demais disciplinas do currículo escolar (interdisciplinar). De fato, conforme apontado nas DCNEM (BRASIL, 1998), interdisciplinaridade e contextualização são princípios organizadores do currículo que permitem ampliar as inúmeras possibilidades de interação entre disciplinas e entre áreas nas quais estas disciplinas estão agrupadas.

Neste contexto, os enfoques multi, trans e interdisciplinares são as formas de integração mais encontradas nas propostas curriculares e utilizadas pelos professores desta pesquisa. O currículo com enfoque multidisciplinar é aquele que trata de diferentes campos do conhecimento, porém, sem o estabelecimento de conexões sistemáticas entre os respectivos conteúdos; já no currículo com enfoque interdisciplinar, estas conexões são feitas de modo sistemático. O currículo com enfoque transdisciplinar busca integrar os conteúdos por meio de temas que transversalizam o currículo, podendo estabelecer ou não conexões sistemáticas entre eles. Conforme já visto nos resultados desta pesquisa, na PCEC (SÃO PAULO, 1998), o estudo do ambiente é feito por meio de uma abordagem interdisciplinar, na qual a noção de ambiente é construída a partir da apreensão de seus componentes e processos e de suas múltiplas relações com os aspectos físicos, químicos, geológicos, biológicos, tecnológicos e socioeconômicoculturais; enquanto, nos PCNEF (BRASIL, 1988), há uma proposta de abordagem transdisciplinar, por meio de temas transversais que, sem romperem com a estrutura disciplinar, propõem a abordagem de temas abrangentes que perpassam ou transversalizam todas as disciplinas escolares.

De um modo ou outro, é importante atentar para o fato de que as disciplinas e áreas podem ser interligadas, mas não podem ser diluídas e nem eliminadas. É preciso reconhecer o caráter disciplinar do conhecimento, já que cada campo do conhecimento possui sua lógica e sua própria metodologia de investigação. Assim, é preciso orientar e organizar o aprendizado, de forma que cada disciplina, em sua especificidade, possa desenvolver conhecimentos integrados, examinando o objeto de estudo disciplinar em seus diferentes contextos de significação, conforme apontam as perspectivas de ensino aqui desenvolvidas. 
Kato, D. S.; Kawasaki, C. S.

Em relação à terceira categoria "Ciência", que busca situar ou relacionar o conhecimento específico aos conhecimentos das ciências-referência (Biologia, Química, Física e Geociências), parte-se da crítica de uma visão de ciência como algo externo e separado da sociedade e neutra quanto ao conhecimento que produz. Busca-se, assim, uma concepção mais realista da ciência, não só como uma coleção de conhecimentos (produtos), mas, também, como uma maneira peculiar de produzi-los (processos). Certamente, a concepção de ensino de ciências deve estar coerente com esta perspectiva de ciência, o que não é uma tarefa simples, conforme aponta a própria história do ensino de ciências no Brasil.

O movimento de inovação no ensino de ciências, que buscou modificar o ensino tradicional de ciências, com ênfase no produto da ciência e na transmissão de um conteúdo científico pronto e acabado, para um ensino ativo, com ênfase no processo da ciência, trouxe como herança a vivência do método científico pelo aluno. Nas décadas de 1960 e 1970, a incorporação da vivência do método científico no ensino de ciências, enquanto uma atividade científica simulada - em que o aluno reproduz a suposta sequência padronizada de etapas experimentais que seria necessária à obtenção de novos conhecimentos, chamado de método da redescoberta - trouxe, pelo menos, dois equívocos. O primeiro foi o de deturpar a compreensão sobre o processo científico, reduzindo-o a algo esquemático e padronizado, capaz de conduzir, com segurança, as respostas certas e definitivas para os problemas científicos. Certamente, tal perspectiva não corresponde ao modo como a ciência produz conhecimentos. $\mathrm{O}$ segundo foi o de transpor diretamente este método científico, nos moldes já mencionados, para situações de ensino, como se ensinar ciências fosse o mesmo que ensinar o método científico a fim de transformar o aluno em um minicientista. É importante conhecer o procedimento da ciência e o(s) método(s) da ciência, para compreendê-la não apenas como produto, mas, também, como um processo; porém a experiência do aluno com o objeto de estudo deve ser algo verdadeiramente experimental, no sentido de que a realidade precisa ser experimentada, vivida e testada, visando desenvolver o complicado processo de formação do pensamento lógico e crítico do estudante.

Na quarta categoria "Ensino", busca-se situar ou relacionar o conhecimento específico a outras formas do conhecimento, como aquelas que vêm do cotidiano do aluno e da sociedade em que ele vive, buscando-se a melhor síntese para a produção do conhecimento escolar. Certamente, não se trata de uma síntese definitiva, mas em constante transformação, já que responde a objetivos educacionais e sociais mais amplos (incluem-se, aqui, os objetivos do ensino de ciências) e às necessidades e características do público escolar a que se destina. Em suma, é no contexto do ensino que se estabelecem as mediações didáticas envolvidas nesta produção do conhecimento escolar e no qual o professor possui um papel fundamental: o de ser o principal sujeito mediador deste processo. Para promover tais mediações, é importante atentar para os seguintes aspectos: 1) conhecer as características das diferentes formas do conhecimento - científico, do senso comum, escolar e outros - que chegam e se constituem na escola; 2) conhecer os diferentes objetos, formas e sujeitos de mediação - tais como, os materiais e recursos didáticos e pedagógicos, os materiais curriculares, o planejamento escolar e os planos de ensino, os livros didáticos, os métodos e estratégias de ensino, os professores, os alunos etc. - para compreender os processos pelos quais os conhecimentos escolares são produzidos e que implicações estes podem trazer para o ensino, e 3) planejar o ensino, selecionan- 
As concepções de contextualização do ensino...

do e organizando conteúdos e métodos de ensino que respondam às questões que surgem nos itens anteriores.

Quanto à quinta e última categoria, "contextos histórico, social e cultural", buscase relacionar ou situar o conhecimento específico na sociedade. Partindo-se da premissa de que a ciência é uma atividade humana, sendo, por isso, histórica, coletiva e impregnada pelas características sociais de sua época, busca-se contextualizar o conhecimento científico (específico), situando-o historicamente no tempo e no espaço, para se compreender como se deu a sua evolução.

Contudo, há equívocos nesta abordagem histórica que acabam desvirtuando esta perspectiva. Um deles refere-se à abordagem linear e factual da história da ciência, que ignora as contradições inerentes ao processo da ciência; e o outro se refere à questão da relação ciência, tecnologia e sociedade, que tem sido comumente deturpada, pela forma parcial com que tem sido tratada, enfatizando-se o aspecto tecnológico em detrimento de outros aspectos. Sendo assim, é importante adotar-se uma abordagem que procure analisar criticamente estas relações envolvidas, na perspectiva de uma história crítica ou de uma ciência histórica.

Em suma, as possibilidades de mediações didáticas que o professor poderá encontrar

a partir das diferentes concepções de contextualização do ensino podem ser muitas, sendo estas apenas algumas delas. O importante é o professor estar atento a elas, para que ele possa assumir, de fato, o seu papel de mediador (ativo) dos processos de ensino e aprendizagem.

\section{Referências}

BARDIN, L. Análise de conteúdo. Lisboa: Edições 70, 2009.

BRASIL. Ministério da Educação. Conselho Nacional de Educação. Diretrizes curriculares nacionais para o ensino médio. Brasília: MEC/CNE, 1998.

Lei n. 9.394, de 20 de dezembro de 1996. Estabelece as diretrizes e bases da educação nacional. Diário Oficial [da] República Federativa do Brasil, Brasília, DF, 23 dez. 1996. Seção 1.

. Ministério da Educação. Secretaria de Educação Fundamental. Parâmetros Curriculares Nacionais: Ciências Naturais. Brasilia: MEC/SEF, 1998.

Ministério da Educação. Secretaria de Educação Média e Tecnológica. Parâmetros Curriculares Nacionais: Ensino Médio. Brasília: MEC/SEMTEC, 1999.

BOGDAN, R.; BIKLEN, S. Investigação qualitativa em educação: uma introdução à teoria e aos métodos. Porto: Porto Editora, 1994.

DEWEY, J. Democracia e educação: introdução à filosofia da educação. 3. ed. Trad. Godofredo Rangel e Anísio Teixeira. São Paulo: Nacional, 1959.

FRACALANZA, H.; AMARAL, I. A.; GOUVEIA, M. S. F. O ensino de ciências no primeiro grau. São Paulo: Atual, 1986. 
Kato, D. S.; Kawasaki, C. S.

LIMA, J. F. L.; PINA, M. S. L.; BARBOSA, R. M. N.; JÓFOLI, Z. M. S. A contextualização no ensino de cinética química. Química Nova na Escola, Rio de Janeiro, n. 11, p. 27-29, 2000 .

LOPES, A. C. Os parâmetros curriculares nacionais para o ensino médio e a submissão ao mundo produtivo: o caso do conceito de contextualização. Educação \& Sociedade, Campinas, v. 23, n. 80, p. 386-400, 2002.

LOPES, A. C.; GOMES, M. M.; LIMA, I. S. Diferentes contextos na área de ciências da natureza, matemática e suas tecnologias nos parâmetros curriculares nacionais para o ensino médio: integração com base no mercado. In: ENCONTRO NACIONAL DE PESQUISA EM ENSINO DE CIÊNCIAS, 2., 2001, Atibaia. Anais... Atibaia: Abrapec, 2001. 1 cd-rom. MOYSES, L. Aplicações de Vigotsky à educação matemática. Campinas: Papirus, 1997.

RAMOS, M. N. A educação profissional pela Pedagogia das Competências: para além da superfície dos documentos oficiais. Educação \& Sociedade, Campinas, v. 23, n. 80, p. $405-427,2002$.

RODRIGUES, C. L.; AMARAL, M. B. Problematizando o óbvio: ensinar a partir da realidade do aluno. In: CONGRESSO DA ASSOCIAÇÃO NACIONAL DE PÓSGRADUAÇÃO E PESQUISA EM EDUCAÇÃO, 19., Caxambu, 1996. Anais... Caxambu: Anped, 1996. p. 197.

SÃO PAULO (Cidade). Secretaria Municipal de Educação. Diretoria de Orientação Técnica. Movimento de reorientação curricular: Ciências - visão de área. São Paulo: SME/DOT, 1992.

SÃO PAULO (Estado). Secretaria da Educação. Coordenadoria de Estudos e Normas Pedagógicas. Proposta curricular para o ensino de Biologia: $2^{\circ}$ grau. 2. ed. São Paulo: SE/CENP, 1988.

Secretaria da Educação. Coordenadoria de Estudos e Normas Pedagógicas.

Proposta curricular para o ensino de ciências e programas de saúde: $1^{\circ}$ grau. 2 . ed. São Paulo: SE/CENP, 1991.

STEIN, D. Situated learning in adult education. ERIC Digests, Columbus, OH, n. 195, p. 1-7, 1998. Disponível em: <http://www.ericdigests.org/1998-3/adult-education.html>. Acesso em: 07 nov. 2009.

VYGOTSKY, L. S. Pensamento e linguagem. São Paulo: Martins Fontes, 1987.

Artigo recebido em setembro de 2010 e aceito em dezembro de 2010. 